\title{
PREVALÊNCIA DE ANTICORPOS ANTI Anaplasma marginale (RICKETTSIALES: ANAPLASMATACEAE) EM BOVINOS NA MESORREGIÃO DO MÉDIO PARAÍBA
}

\author{
PREVALENCE OF ANTIBODIES AGAINST Anaplasma marginale (RICKETTSIALES: \\ ANAPLASMATACEAE) IN CATTLE IN THE "MÉDIO PARAÍBA" \\ MESOREGION, BRAZIL
}

\author{
José Carlos Pereira de Souza ${ }^{1}$ Cleber Oliveira Soares ${ }^{1}$ Claudio Roberto Madruga ${ }^{2}$ \\ Carlos Luiz Massard ${ }^{3}$
}

RESUMO

Realizou-se a pesquisa de anticorpos da classe $\operatorname{Ig} G$ antiAnaplasma marginale através do ensaio de imunoadsorção enzimática (ELISA) indireto em 223 amostras de soros de bovinos provenientes de oito municípios da mesorregião do Médio Paraíba, estado do Rio de Janeiro. A prevalência observada foi de 98,21\%. Das amostras positivas, 36,32\% possuíam o título de $1: 500,43,50 \%$ com título de 1:1000, $12,56 \%$ com título de 1:2000, 3,59\% com título de 1:4000, 1,79\% com título de 1:8000, $0,45 \%$ com título de 1:16000 e 1,79\% foram soronegativos. Procedeu-se a avaliação da prevalência por grupos etários de 1 a 3 anos $(n=53), 3$ a 6 anos $(n=71) e>6$ anos $(n=99)$, na qual $96,23 \%, 100 \%$ e 97,98\% dos animais foram soropositivos, respectivamente. A análise em relação à aptidão zootécnica revelou que $100 \%$ dos animais com aptidão para corte $(n=38)$ e 97,84\% com aptidão para leite $(n=185)$ reagiram ao ensaio. Dos animais estudados, 183 eram fêmeas e 40 machos e, destes, 98,91\% e 95,00\% foram positivos, respectivamente. A análise estatística demonstrou não haver diferença significativa $(P>0,05)$, de prevalência, entre idades, aptidões zootécnicas e entre sexos. Houve diferença significativa $(P<0,0001)$ de soropositivos entre os municípios. A região foi caracterizada como uma área de estabilidade enzoótica para A. marginale.

Palavras-chave: Anaplasma marginale, soroprevalência, anaplasmose bovina, mesorregião do Médio $\mathrm{Pa}$ raíba.

\section{SUMMARY}

Serumprevalence of antibodies against Anaplasma
marginale were studied by the indirect Enzyme-Linked
Immunosorbent Assay (ELISA). Sera samples from 223 bovines of eight municipalities in the "Médio Paraíba" mesorregion, in the state of Rio de Janeiro state, were analysed. The prevalence showed $98.21 \%$ of positives, of which were: $36.32 \%$ with a titre of $1: 500,43.50 \%$ of $1: 1000,12.56 \%$ of $1: 2000,3.59 \%$ of $1: 4000$, $1.79 \%$ of $1: 8000,0.45 \%$ of $1: 16000$, and $1.79 \%$ were negative. The evaluation was done within three age groups: 1 to 3 years ( $n$ $=53), 3$ to 6 years $(n=71)$ and $>6$ years $(n=99)$, of which $96.23 \%, 100 \%$ and $97.98 \%$ were positive, respectively. Regarding to the breed, $100 \%$ of beef cattle $(n=38)$ and $97.84 \%$ of dairy cattle $(n=185)$, were positive. According to the sex, $98.91 \%$ of the females $(n=183)$ and $95.00 \%$ of the males $(n=40)$, were positive. There were no significant differences $(P>0.05)$ between the prevalence of age groups, breeding types and sexes. There were significant differences $(P<0.0001)$ among the serumprevalence in the municipalities. The region was characterized as an enzootically stable area to A. marginale.

Key words: Anaplasma marginale, seroprevalence, bovine anaplasmosis, "Médio Paraíba” mesoregion

\section{INTRODUÇÃO}

A anaplasmose bovina é uma enfermidade causada, principalmente, pela rickettsia intraeritrocítica Anaplasma marginale Theiler, 1910. Esse agente é transmitido mecanicamente por dípteros hematófagos e por fômites e, biologicamente, por carrapatos ixodídeos. Entre os

\footnotetext{
${ }^{1}$ Doutorando do Curso de Pós-graduação em Medicina Veterinária - Parasitologia Veterinária, Universidade Federal Rural do Rio de Janeiro (UFRRJ). Km 47, Rodovia Rio - São Paulo, Seropédica, RJ 23890-000. E-mail: csoares@ufrrj.br. Autor para correspondência. ${ }^{2}$ Pesquisador do Centro Nacional de Pesquisa de Gado de Corte - Embrapa, Campo Grande, MS.

${ }^{3}$ Professor Titular do Departamento de Parasitologia Animal, UFRRJ. 
carrapatos pode haver a transmissão transestadial, e para Boophilus microplus, o macho tem papel relevante (RIBEIRO, 1991; MASSARD et al., 1998).

A enfermidade é caracterizada por febre elevada (acima de $40^{\circ} \mathrm{C}$ ), palidez de mucosas, icterícia marcada, desidratação, perda de apetite, coprostase e fezes ressequidas; a anemia é decorrente da massiva hemocaterese; pode ocorrer, ainda, aborto, esterilidade e queda de produção (TOKARNIA \& DÖBEREINER, 1962; KESSLER et al., 1992).

A anaplasmose possui ampla distribuição geográfica e ocorre tanto em regiões de clima tropical e subtropical como em zonas de clima temperado (MOREL, 1989; DALGLIESH et al., 1990). Nos Estados Unidos da América, essa hemopararasitose é responsável por perdas econômicas na ordem de 100 milhões de dólares anuais (McCALLON, 1973). No Brasil, os prejuízos determinados por Anaplasma sp. não foram estimados. No entanto, a anaplasmose é uma das principais causas de mortalidade de bezerros no país (TOKARNIA \& DÖBEREINER, 1962; RIBEIRO et al., 1983; MADRUGA et al., 1984).

Para se estabelecer um programa de controle da anaplasmose, faz-se necessário o conhecimento epidemiológico dessa enfermidade. A situação epidemiológica de determinada área pode ser caracterizada, principalmente, de três formas: áreas de estabilidade enzoótica, instabilidade enzoótica e situação de área marginal (MAHONEY, 1975; KESSLER et al., 1992). Para se obter essas informações, devem-se utilizar métodos de diagnósticos práticos e eficazes. O teste do cartão (TC) e a prova de imunofluorescência indireta (IFI) são técnicas amplamente utilizadas em levantamentos sorológicos (RIBEIRO et al., 1984; OLIVEIRA et al., 1992); entretanto, o ensaio imunoenzimático de adsorção (ELISA) indireto possui melhor desempenho em relação ao TC e a IFI (ARAÚJO $\boldsymbol{e t}$ al., 1998).

Embora A. marginale apresente ampla distribuição, em muitas regiões fisiográficas do Brasil não se conhece a condição epidemiológica da anaplasmose, como é a situação do estado do Rio de Janeiro (RJ). Assim, este estudo teve por propósito proceder um inquérito sorológico para $\boldsymbol{A}$. marginale em bovinos na mesorregião do Médio Paraíba, RJ.

\section{MATERIAL E MÉTODOS}

O estudo foi desenvolvido com amostras de soros bovino provenientes de oito municípios da mesorregião do Médio Paraíba do estado do Rio de Janeiro, conforme divisão político-administrativa da Fundação Cide (CIDE, 1997). Essa região possui uma população bovina, aproximada, de 211.658 cabeças, em uma área total de 388.259 hectares e com produção leiteira de 93.098.000 litros anuais. A mesorregião está localizada entre as latitudes mínimas de $22^{\circ} 10^{\prime} 03^{\prime \prime}$ sul e $43^{\circ} 35^{\prime} 08^{\prime \prime}$ oeste e, as latitudes máximas de $22^{\circ} 43^{\prime} 23^{\prime \prime}$ sul e $44^{\circ} 33^{\prime} 48^{\prime \prime}$ oeste (CIDE, 1997).

De acordo com a conveniência e a facilidade de acesso às propriedades, foram colhidas, através de venopunção jugular, amostras sangüíneas de 223 bovinos jovens e adultos, maiores que um ano de idade, puros Bos taurus ou mestiço B. taurus $\mathrm{x} \boldsymbol{B}$. indicus, aparentemente sadios. Os soros obtidos foram aliquotados em tubos tipo eppendorf e armazenados à $-20{ }^{\circ} \mathrm{C}$ para posterior análise sorológica. A amostragem foi realizada coletando um número maior ou igual a $0,1 \%$ da população de bovinos da mesorregião, conforme estudos anteriores (SOUZA et al., 2000).

As amostras de soro $(n=223)$ estão distribuídas entre oito municípios da seguinte forma: Rio das Flores $(n=21)$, Piraí $(n=9)$, Itatiaia $(n=16)$, Rio Claro $(n=10)$, Barra do Piraí $(n=25)$, Valença (n = 29), Barra Mansa $(n=89)$ e Resende ( $n=24)$. Procedeu-se o agrupamento dos animais de acordo com a faixa etária: 1 a 3 anos $(\mathrm{n}=53), 3$ a 6 anos (n =71) e > 6 anos $(\mathrm{n}=99)$; de acordo com a aptidão zootécnica: animais com aptidão para corte $(\mathrm{n}=38)$ e animais com aptidão para leite $(\mathrm{n}=185)$; de acordo com o sexo: machos $(n=40)$ e fêmeas $(n=183)$.

Procedeu-se a pesquisa de anticorpos da classe IgG contra $\boldsymbol{A}$. marginale através do ensaio ELISA indireto. Microplacas de 96 orifícios para titulação foram sensibilizadas com extrato total antigênico de $\boldsymbol{A}$. marginale obtido segundo técnica descrita por ARAÚJO et al. (1998), diluído em tampão carbonato $\mathrm{pH} 9,6$. Os soros controles negativos, controles positivos e os soros testes foram diluídos a 1:500 em tampão salino fosfatado com Tween 20 a $0,05 \%$ (PBST) pH 7,4. Foi utilizado, como conjugado, IgG de coelho anti IgG bovina marcada com fosfatase alcalina (Sigma Chemical), diluído em PBST pH 7,4. Como substrato-cromógeno foi utilizado o paranitrofenil fosfato (Sigma Chemical) diluído em tampão glicina $\mathrm{pH}$ 10,5. A leitura do ensaio foi realizada em espectrofotômetro multicanal para microplacas de 96 orifícios calibrado ao comprimento de onda de $405 \eta \mathrm{m}$. 
A análise estatística dos dados foi realizada utilizando os testes de Fisher e Qui-quadrado $\left(\chi^{2}\right)$. A linha de corte (cut-off), para o ELISA, foi determinada através da média aritmética mais três vezes o desvio padrão das densidades ópticas dos soros controles negativos.

\section{RESULTADOS}

Ao analisarem as 223 amostras de soro, observou-se que 219 $(98,21 \%)$ foram soropositivas com anticorpos anti $\boldsymbol{A}$. marginale. Das amostras positivas, $36,32 \%$ possuíam título de 1:500, 43,50\% com título de $1: 1000,12,56 \%$ com título de 1:2000, $3,59 \%$ com título de 1:4000, 1,79\% com título de 1:8000, 0,45\% com título de 1:16000 e 1,79\% foram soronegativas (Tabela 1).

A soroprevalência, de acordo a faixa etária, revelou que $96,23 \%$ dos animais com idade entre 1 a 3 anos, 100\% com idade entre 3 a 6 anos e 97,98\% dos animais com idade > 6 anos foram reagentes positivos. Não houve diferença estatística significativa $(\mathrm{P}>0,05)$ entre as faixas etárias (Tabela 2).

A avaliação, quanto à aptidão zootécnica, demonstrou que $100 \%$ dos animais com aptidão para corte e $97,84 \%$ dos animais com aptidão para leite

Tabela 1 - Prevalência sorológica de anticorpos antiAnaplasma marginale em bovinos $(n=223)$ da mesorregião do Médio Paraíba, RJ. Determinações realizadas pela prova ELISA indireto.

\begin{tabular}{|c|c|c|c|c|}
\hline \multirow[t]{2}{*}{ Título } & \multirow[t]{2}{*}{ Positivos (n) } & \multicolumn{2}{|c|}{ Prevalência } & \multirow[t]{2}{*}{ Negativos (n) } \\
\hline & & Relativa & Absoluta & \\
\hline $1: 500$ & 81 & $36,99 \%$ & $36,32 \%$ & --- \\
\hline $1: 1000$ & 97 & $44,29 \%$ & $43,50 \%$ & --- \\
\hline 1:2000 & 28 & $12,78 \%$ & $12,56 \%$ & --- \\
\hline 1:4000 & 8 & $3,65 \%$ & $3,59 \%$ & --- \\
\hline $1: 8000$ & 4 & $1,83 \%$ & $1,79 \%$ & --- \\
\hline $1: 16000$ & 1 & $0,46 \%$ & $0,45 \%$ & --- \\
\hline Total positivos & 219 & $100 \%(219 / 219)$ & $98,21 \%(219,223)$ & --- \\
\hline Total negativos & --- & --- & $1,79 \%$ & 4 \\
\hline
\end{tabular}

foram soropositivos (Tabela 3). Não houve diferença significativa $(\mathrm{P}>0,05)$ entre as aptidões zootécnicas.

A análise estatística, de acordo com o sexo, revelou a soroprevalência relativa de $98,91 \%$ de fêmeas positivas e $95,00 \%$ de machos positivos (Tabela 4). Não houve diferença significativa ( $P$ > $0,05)$ entre os sexos.

Para os municípios, a soroprevalência foi de $100 \%$ em Piraí, $100 \%$ em Rio das Flores, $100 \%$ em Barra do Piraí, 100\% em Barra Mansa, 81,25\% em Itatiaia, $90 \%$ em Rio Claro, $100 \%$ em Valença e $100 \%$ em Resende. Houve diferença significativa (P $<0,0001)$ de soropositivos, entre os municípios, segundo o teste $\chi^{2}$ (Figura $1)$.

\section{DISCUSSÃO}

A prevalência de anticorpos antiA. Marginale, encontrada no presente estudo, é considerada alta, epidemiologicamente $\quad(\geq 75,0 \%)$ (MAHONEY, 1975). Embora existam fatores de resistência à anaplasmose, como raça, idade e condição imunológica (MOREL, 1989), a taxa de inoculação de $\boldsymbol{A}$. marginale por $\boldsymbol{B}$. microplus e a possível participação de outras fontes de transmissão, como fômites e dípteros hematófagos, justificam a caracterização da 
Tabela 3 - Prevalência sorológica de anticorpos antiAnaplasma marginale em bovinos ( $n=223$ ), segundo a aptidão zootécnica, da mesorregião do Médio Paraíba, RJ. Determinações realizadas pela prova ELISA indireto.

\begin{tabular}{|c|c|c|c|c|}
\hline & \multicolumn{4}{|c|}{ Aptidão zootécnica } \\
\hline & \multicolumn{2}{|c|}{ Corte $(\mathrm{n}=38)^{*}$} & \multicolumn{2}{|c|}{ Leite $(\mathrm{n}=185)^{*}$} \\
\hline & Relativa & Absoluta & Relativa & Absoluta \\
\hline Positivo & $100,00 \%(38 / 38)$ & $17,04 \%(38 / 223)$ & $97,84 \%(181 / 185)$ & $81,17 \%(181 / 223)$ \\
\hline Negativo & $0,00 \%(0 / 38)$ & $0,00 \%(0 / 223)$ & $2,16 \%(4 / 185)$ & $1,79 \%(4 / 223)$ \\
\hline Total & $100 \%(38 / 38)$ & $17,04 \%(38 / 223)$ & $100 \%(185 / 185)$ & $82,96 \%(185 / 223)$ \\
\hline
\end{tabular}

*Não houve diferença significativa $(\mathrm{P}>0,05)$ entre as aptidões zootécnicas, segundo o teste $\chi^{2}$ e o teste de Fisher.

mesorregião do Médio Paraíba como área de estabilidade enzoótica.

A não observação de diferença estatística nas prevalências, segundo os grupos etários, as aptidões zootécnicas e os sexos, faz inferir que esses parâmetros não interferem na condição de estabilidade dessa mesorregião.

Embora tenha ocorrido diferença estatística na mesorregião, pois a prevalência de soropositivos no município de Itatiaia diferiu dos demais, esse município também apresentou uma situação de estabilidade enzoótica $(81,25 \%)$ para $\boldsymbol{A}$. marginale.

A soroprevalência dos municípios, obtida no presente trabalho, assemelha-se àquelas registradas em outros estados de diferentes regiões do país, onde predominam áreas de estabilidade enzoótica

Tabela 4 - Prevalência sorológica de anticorpos antiAnaplasma marginale em bovinos $(\mathrm{n}=223)$, segundo o sexo, da mesorregião do Médio Paraíba, RJ. Determinações realizadas pela prova ELISA indireto.

\begin{tabular}{|c|c|c|c|c|}
\hline & \multicolumn{4}{|c|}{ Sexo } \\
\hline & \multicolumn{2}{|c|}{ Fêmea $(\mathrm{n}=183)^{*}$} & \multicolumn{2}{|c|}{ Macho $(n=40) *$} \\
\hline & Relativa & Absoluta & Relativa & Absoluta \\
\hline Positivo & $98,91 \%(181 / 183)$ & $81,16 \%(181 / 223)$ & $95,00 \%(38 / 40)$ & $17,04 \%(38 / 223)$ \\
\hline Negativo & $1,09 \%(2 / 183)$ & $0,90 \%(2 / 223)$ & $5,00 \%(2 / 40)$ & $0,90 \%(2 / 223)$ \\
\hline Total & $100 \%(183 / 183)$ & $82,06 \%(183 / 223)$ & $100 \%(40 / 40)$ & $17,94 \%(40 / 223)$ \\
\hline
\end{tabular}

*Não houve diferença significativa $(\mathrm{P}>0,05)$ entre os sexos, segundo o teste $\chi^{2}$ e o teste de Fisher. para $\boldsymbol{A}$. marginale. Em um estudo realizado na Zona da Mata do estado de Minas Gerais, a prevalência de anticorpos anti $\boldsymbol{A}$. marginale foi de $81,10 \%$ (RIBEIRO et al., 1984), e, no estado de Santa Catarina, o percentual de positividade observada foi de $86,00 \%$ (DALAGNOL $\boldsymbol{e t}$ $\boldsymbol{a l} .$, 1995), ambos determinados pela IFI. Os resultados desse estudo foram semelhantes aos encontrados em rebanhos leiteiros na Bahia, através de ELISA indireto, IFI e teste de conglutinação rápida $(96,90 \%, 97,20 \%$ e $91,00 \%$ de positividade, respectivamente) (ARAÚJO et al., 1998).

Poucas áreas do Brasil, até o momento, foram caracterizadas como de instabilidade para $\boldsymbol{A}$. marginale. Entre elas, o estado de Sergipe para as regiões climáticas do tipo árida, semi-árida, transição semi-árida e transição subúmida, onde a prevalência média foi de 16,30\% (OLIVEIRA et al., 1992). Outra região considerada instável é a microrregião de Bagé, estado do Rio Grande do Sul, na qual a prevalência observada de animais reagentes para A. marginale foi de 64,00\% (ARTILES $\boldsymbol{e t}$ al., 1995). Em ambas as pesquisas, foi utilizado o TC na análise sorológica. Nessas duas microrregiões, as condições climáticas são desfavoráveis ao desenvolvimento dos vetores de A. marginale. Tanto em regiões de estabilidade quanto de instabilidade enzoótica, para hemoparasitos de bovinos, o ELISA indireto mostrou especificidade $\mathrm{e}$ sensibilidade iguais ou superiores à IFI. No entanto, o ELISA é mais adequado para estudos soroepidemiológicos por garantir maior amplitude de titulação (MADRUGA et $\boldsymbol{a l}$., 1997; ARAÚJO et al., 1998; SOUZA et al., 2000).

Os presentes resultados indicam que nessa circunstância epidemiológica a ocorrência de anaplasmose clínica é mínima, tornando-se necessária, apenas, a imunização de animais importados de outras áreas ou regiões de instabilidade enzoótica. 


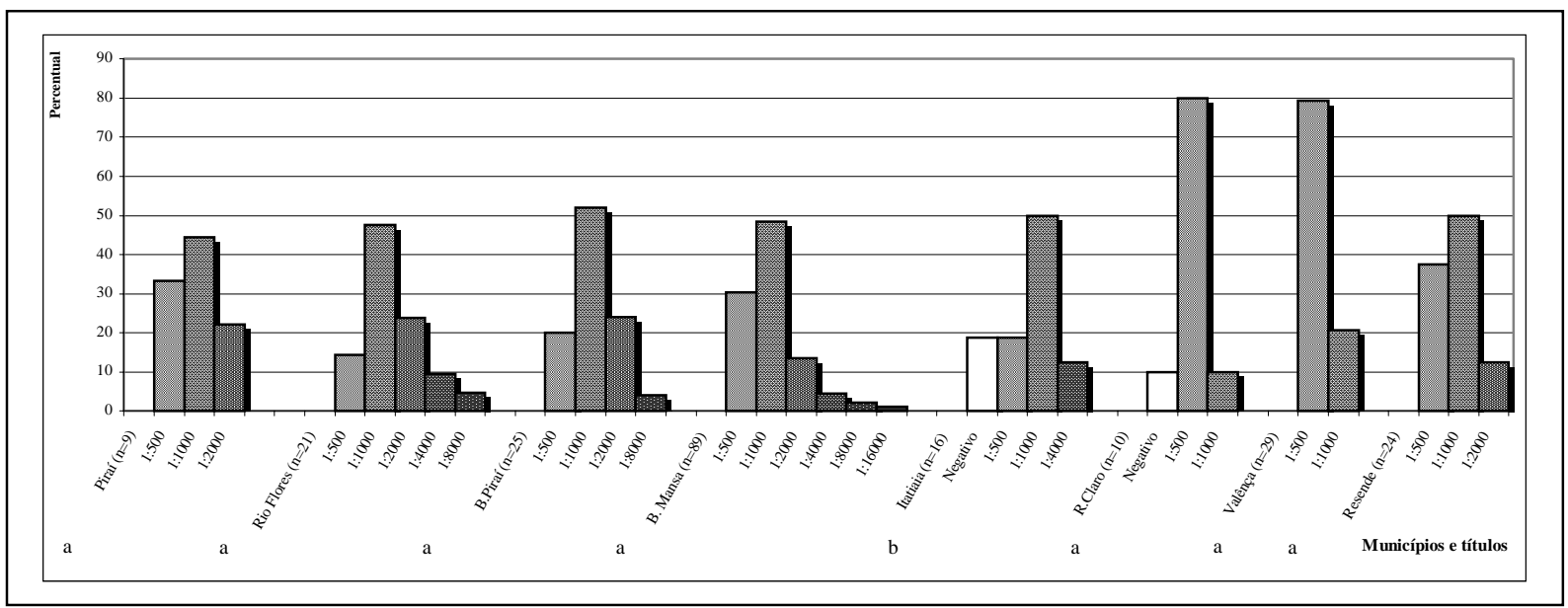

Houve diferença significativa $(\mathrm{P}<0,0001)$ de soropositivos entre os municípios, representada por letras diferentes, segundo o teste $\chi^{2}$.

Figura 1 - Prevalência de anticorpos antiAnaplasma marginale em bovinos ( $\mathrm{n}=223)$ da mesorregião do Médio Paraíba, RJ; determinações realizadas pela prova ELISA indireto. Distribuição segundo os municípios estudados.

\section{REFERÊNCIAS BIBLIOGRÁFICAS}

ARAÚJO, F.R., MADRUGA, C.R., BASTOS, P.A.S., et al Freqüência de anticorpos antiAnaplasma marginale em rebanhos leiteiros da Bahia. Arq Bras Med Vet Zootec, v.50, n.3. p.243-246, 1998.

ARTILES, J., ALVES-BRANCO, F.P.J., MARTINS, J.R., et al. Prevalência de Babesia bovis, B. bigemina e Anaplasma marginale no município de Bagé, RS. Rev Bras Parasitol Vet, v.4, n.2, Supl.1, p.179, 1995.

CIDE. Território. Rio de Janeiro: Fundação de Informação e Dados do Rio de Janeiro, 1997. 80p.

DALAGNOL, C.A., MARTINS, E., MADRUGA, C.R Prevalência de anticorpos contra Babesia bovis, Babesia bigemina, Anaplasma marginale em bovinos de corte na região de clima Cfb. Rev Bras Parasitol Vet, v.4, n.2, Supl.1, p.220, 1995.

DALGLIESH, R.J., JORGENSEN, W.K., DE VOS, A.J. Australian frozen vaccines for the control of babesiosis and anaplasmosis in cattle - A review. Trop Anim Hlth Prod, v.22, p.44-52, 1990.

KESSLER, R.H., SCHENK, M.A.M., MADRUGA, C.R., $\boldsymbol{e}$ t al Tristeza parasitária dos bovinos (TPB). In: CHARLES, T.P., FURLONG, J. Doenças parasitárias dos bovinos de leite. Coronel Pacheco, MG : Embrapa-CNPGL, 1992. p.1-30.

MADRUGA, C.R., GOMES, R.F., SCHENK, M.A.M. Etiologia de algumas doenças de bezerros de corte no estado de Mato Grosso do Sul. Campo Grande, MS : EmbrapaCNPGC, 1984. 27p. (Circular Técnica, 15).
MADRUGA, C.R., MARQUES, A.P.C., QUEIROZ, R.A., $\boldsymbol{e}$ t al Avaliação de um teste ELISA para detecção de anticorpos contra Babesia bigemina em bovinos de áreas de estabilidade e instabilidade enzoótica. Rev Bras Parasitol Vet, v.6, n.2, Supl.1, p.302, 1997.

MAHONEY, D.F. The diagnosis of babesiosis in Australia. In: WELLS, E.A. Workshop on hemoparasites (anaplasmosis and babesiosis). Cali, Colombia : CIAT, 1975. p.49-62.

MASSARD, C.L., SOARES, C.O., FONSECA, A.H., $\boldsymbol{e} \boldsymbol{t} \boldsymbol{a l}$. Curso sobre controle de carrapato em bovino. Campo Grande, MS : Embrapa-CNPGC, 1998. Tristeza parasitária bovina: histórico, biologia, e modalidades de transmissão de Babesia bovis, Babesia bigemina e Anaplasma marginale aos bovinos: p.77-90.

McCALLON, B.R. Prevalence and economic aspects of anaplasmosis. In: NATIONAL ANAPLASMOSIS CONFERENCES, 1973, Stillwater, Heritage. Proceedings... Stillwater : USDA, 1973. p.1.

MOREL, P.C. Manual of tropical veterinary parasitology. Wallingford, UK : CAB International, 1989. 473p.

OLIVEIRA, A.A., PEDREIRA, P.A.S., ALMEIDA, M.F.R.S. Doenças de bezerros. II. Epidemiologia da anaplasmose no estado de Sergipe. Arq Bras Med Vet Zootec, v.44, n.5, p.377-386, 1992.

RIBEIRO, M.F.B., SALCEDO, J.H.P., SANTOS, J.L, et al. Inquérito de opinião com criadores da Zona da Mata do estado de Minas Gerais: I. Alguns fatores associados com mortalidade de bezerros. Arq Bras Med Vet Zootec, v.35, p.547-556, 1983. 
RIBEIRO, M.F.B., PATARROYO, J.H., SANTOS, J.L., $\boldsymbol{e} \boldsymbol{t} \boldsymbol{a}$. Epidemiologia da anaplasmose bovina no estado de Minas Gerais. I. Prevalência de anticorpos aglutinantes e fluorescentes na Zona da Mata. Arq Bras Med Vet Zootec, v.36, p.425-432, 1984.

RIBEIRO, M.F.B. Morfologia, evolução e reprodução do Anaplasma marginale Theiler, 1910 em células epiteliais intestinais de teleóginas de Boophilus microplus (Canestrini, 1887). Estudo ao microscópio óptico e eletrônico.
Belo Horizonte, MG, 1991. 134p. Tese (Doutorado em Parasitologia) - Curso de Pós-graduação em Parasitologia, Universidade Federal de Minas Gerais, 1991.

SOUZA, J.C.P., SOARES, C.O., SCOFIELD, A., et al. Soroprevalência de Babesia bigemina em bovinos na mesorregião Norte Fluminense. Pesq Vet Bras, v.20, n.1, p.26-30, 2000.

TOKARNIA, C.H., DÖBEREINER, J. A importância da anaplasmose em nossos bezerros e as medidas de seu controle. Veterinária, v.15, n.3-4, p.11-19, 1962.

Ciência Rural, v. 31, n. 2, 2001. 